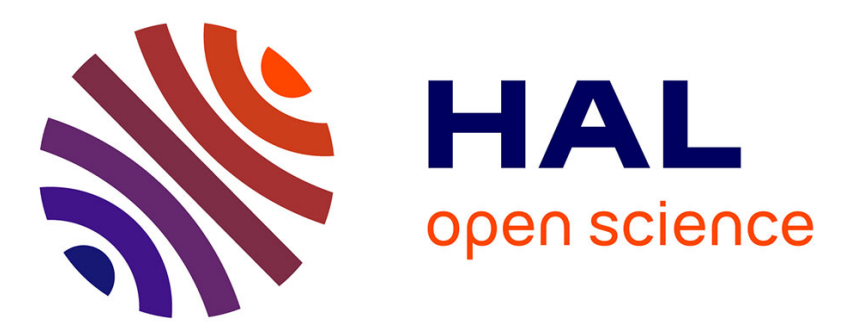

\title{
Direct green extraction of volatile aroma compounds using vegetable oils as solvents: Theoretical and experimental solubility study
}

Ying Li, Anne-Sylvie Fabiano-Tixier, Christian Ginies, Farid Chemat

\section{To cite this version:}

Ying Li, Anne-Sylvie Fabiano-Tixier, Christian Ginies, Farid Chemat. Direct green extraction of volatile aroma compounds using vegetable oils as solvents: Theoretical and experimental solubility study. LWT - Food Science and Technology, 2014, 59, pp.724-731. 10.1016/j.lwt.2014.05.064 . hal02634276

\section{HAL Id: hal-02634276 \\ https://hal.inrae.fr/hal-02634276}

Submitted on 27 May 2020

HAL is a multi-disciplinary open access archive for the deposit and dissemination of scientific research documents, whether they are published or not. The documents may come from teaching and research institutions in France or abroad, or from public or private research centers.
L'archive ouverte pluridisciplinaire HAL, est destinée au dépôt et à la diffusion de documents scientifiques de niveau recherche, publiés ou non, émanant des établissements d'enseignement et de recherche français ou étrangers, des laboratoires publics ou privés. 


\title{
Direct green extraction of volatile aroma compounds using vegetable oils as solvents: Theoretical and experimental solubility study
}

\author{
Ying Li ${ }^{\text {a, b, * }, \text { Anne Sylvie Fabiano-Tixier }}{ }^{\text {a, b }}$, Christian Ginies ${ }^{\text {a, b }}$, Farid Chemat ${ }^{\text {a, b, * }}$ \\ a Avignon University, UMR408, GREEN Extraction Team, F-84000 Avignon, France \\ b INRA, UMR408, Sécurité et Qualité des Produits d'Origine Végétale, Avignon, F-84000, France
}

Keywords:

Extraction

Volatile aroma compounds

Vegetable oil

Hansen solubility parameters

Multivariate statistical analysis

\begin{abstract}
A B S T R A C T
The current study aimed at evaluation of the dissolving power of various vegetable oils in both theoretical and experimental way for the extraction of volatile aroma compounds (VACs) from basil. The solubility of six main VACs from basil in ten vegetable oils was firstly investigated through a theoretical modeling of their Hansen solubility parameters (HSP), followed by real experimental extractions using vegetable oils as solvents instead of petroleum-based solvents such as dichloromethane. Furthermore, multivariate statistical analyses were performed to partition vegetable oils into clusters referring to their dissolving power of VACs, which could be quantified by gas chromatography-mass spectroscopy (GC-MS) coupling to the headspace solid phase micro-extraction (HS-SPME). The results indicated that the solubility of VACs in enriched vegetable oils was significantly different $(p<0.05)$. Vegetable oils has theoretically and experimentally proved their potential to be alternative solvents for further application in green extraction of natural products, in which sunflower oil gave the best performance.
\end{abstract}

\section{Introduction}

Natural oils from vegetable sources are well recognized essential in human diets because of their nutritional and functional properties against some diseases and microorganisms (Orhan, Ozçelik, \& Sener, 2011). Aromatic plants have been used since ancient times in many fields, from food flavoring to cosmetic and pharmaceutical due to their content of essential oils and other bioactive compounds (Loo \& Richard, 1992; Moldão-Martins et al., 2007; Prakash, 1990). In recent times, there is an increasing interest in enrichment of vegetable oils with herbs or spices as sources of harmless natural antioxidants (Baratta et al., 1998; Lis-Balchin, Deans, \& Eaglesham, 1998; Marinova \& Yanishlieva, 1997; Van Boom, Van der Brugghen, \& Maitland, 2002; Veronezi, Costa, \& Jorge, 2012), which the final aromatized oils namely "flavored oils" are in general for seasoning. These new oils not only improve the nutritional value and sensory characteristics, but also prolong the oil shelf-life due to the presence of specific molecules extracted from the aromatic plants (Gambacorta et al., 2007). The recovery of aroma compounds can be achieved by conventional distillation or solvent extraction with appreciable yields. However, the tedious

* Corresponding authors. Avignon University, UMR408, GREEN Extraction Team, F-84000 Avignon, France. Tel.: +3349014 44 65; fax: +334901444 41 .

E-mail addresses: ying.li@univ-avignon.fr (Y. Li), farid.chemat@univ-avignon.fr (F. Chemat). extraction process and large amount of organic solvents used may cause degradation and contamination of the extracts. In view of this, various innovative extracting techniques have been developed in term of alternative solvents and process intensification (Bousbia et al., 2009; Chalchat \& Ozcan, 2008; Daood et al., 2002; Gouveia, Duarte, Beirão-da-Costa, Bernardo-Gil, \& Moldão-Martins, 2006; Li, Fabiano-Tixier, Tomao, Cravotto, \& Chemat, 2013; Moldão-Martins, Palavra, Beirão-da-Costa, \& Bernardo-Gil, 2000). Chevereau (1998) and Rossignol-Castera (2010) have famously applied microwave to improve the extraction efficiency while retaining the quality and the purity of aromas. Meanwhile, the decomposition or the denaturing of the oil substrate could also be avoided. Concerning consumer acceptability and preference, all the flavored oils were appreciated in a greater extent than the sole oil (Antoun \& Tsimidou, 1997). Although the flavored olive oils with a number of herbs have been widely used in the Mediterranean cuisine and are appreciated for their organoleptic superior quality by the customers, other types of flavored vegetable oils were few introduced in the commercial market due to the limited data regarding the solubility and selectivity of vegetable oils and the relevant extraction process as well.

Traditionally, basil has been used for medicinal treatments such as headaches, diarrhea, constipation (Lee, Umano, Shibamoto, \& Lee, 2005). Several studies have demonstrated the antioxidant and preservative capacities of the bioactive compounds in basil 
essential oil (Bagamboula, Uyttendaele, \& Debevere, 2004). The chemical composition of basil essential oil showed good radicalscavenger properties at room temperature and it could prevent the $\alpha$-tocopherol loss in virgin olive oil at a high temperature (Tomaino et al., 2005). Moreover, a slower increase of oxidation was observed in the flavored oil in comparison with the unflavored one and basil showed the highest antioxidant activity (De Felice, De Leonardis, \& Comes, 1993). Thus basil extracts can be used to replace synthetic antioxidants added in vegetable oils or fatty food sausages. Nonetheless, since many petroleum-origin solvents have been gradually regulated worldwide (e.g. Food and Drug Administration in USA, Registration, Evaluation, Authorization and Restriction of Chemicals in Europe, etc.), they have been widely replaced now by supercritical fluids and ethanol for green extraction of natural products (Chalchat \& Ozcan, 2008; Daood et al., 2002; Gouveia et al., 2006; Moldão-Martins et al., 2000). However, vegetable oils may become more competitive in view of economic, food safety and eco-friendly aspects (Hamed, 2007; Kang \& Sim, 2008; Li et al., 2013; Sun \& Temelli, 2006). For the sake of functional and selective extraction with vegetable oils in future, it is essential to get a better knowledge of the dissolving power and the selectivity of these molecularly complex solvents.

Recently, using Hansen solubility parameters (HSP) as helpful theoretical aid for the solvent selection has been aroused a strong interest in predicting the solubility of natural bioactive compounds in various solvents due to its high accuracy and good interpretability. Hansen partitioned fundamental Hildebrand's energy into three distinctive energy of dispersion, polar and hydrogen bonding, which take a comprehensive consideration of intermolecular force in order to better describe and to explain the interactions between solutes and solvents (Hansen, 2000). Although the HSP of triglycerides of the same kind can be calculated by their chemical structures without considering the varying percentage of their major constituent fatty acids, the theoretical solubility prediction of volatile aroma compounds (VACs) in vegetable oils will not be affected. The aim of this work is to understand the solubilization effect of vegetable oils through theoretical and experimental investigation on their performance in extracting VACs from basil as an example. The predictive HSP of solvents and solutes were compared first for a fast theoretical selection of vegetable oils as alternatives to dichloromethane for the following experiments, in which VACs in aromatized oils were quantified by HS-SPME/ GC-MS afterward. The analytical results were then processed with the help of multivariate statistical analyses so that the optimal oil with a considerable solvency can be determined.

\section{Materials and methods}

\subsection{Materials}

Dried, broken, sweet basil leaves (Ocimum basilicum) were purchased from Herbier du Diois, France. They were mechanically ground into fine powders by passing through a No. 60 mesh screen $(0.25 \mathrm{~mm})$.

Refined sunflower, rapeseed, peanut, olive and grape seed oils were obtained from Lesieur, France. Pure coconut oil was provided by KTC Edibles (Wednesbury, UK). Jojoba and avocado oils were supplied by Oleos (Lunel, France) and Emile Noël (France), respectively. Virgin sunflower and olive oils were obtained from Emile Noël and Mondolio in France.

\subsection{Reagents}

Dichloromethane (purity $\geq 99.9 \%$ ) was purchased from MERCK, Germany. The Glyceryl triheptadecanoate ( $99 \%)$ was provided by
Sigma Aldrich. Estragole standard (>99\%) was obtained from Extrasynthese, France. Standards of linalool, limonene, eugenol, eucalyptol and trans-anethole (>99\%) were supplied by Sigma Aldrich.

\subsection{Fatty acid methyl ester (FAME) analysis}

Fatty acid contents of various vegetable oils were determined according to a modified FAME method (Pingret et al., 2012). $20 \mathrm{mg}$ of each vegetable oil sample was placed into a Pyrex tube fitted with a Teflon-lined cap. Glyceryl triheptadecanoate $\left(\mathrm{C}_{54} \mathrm{H}_{104} \mathrm{O}_{6}\right)$ was used as internal standard. $200 \mu \mathrm{l}$ of toluene was added into the tubes, followed by methylation with $1 \mathrm{~mL}$ of $5 \%$ sulfuric acid in methanol. The mixture was vortex-mixed. The tubes were placed in a Stuart SBH200D block heater from Bibby Sterilin Ltd. (Stone, Staffordshire, UK) at $85^{\circ} \mathrm{C}$ for $90 \mathrm{~min}$. They were then removed and cooled to room temperature before the addition of n-hexane $(1 \mathrm{~mL})$ and $0.9 \%$ sodium chloride solution ( $2 \mathrm{~mL}$ ). The mixture was shaken to allow phase separation, and the supernatant was transferred into vial for further GC-FID analysis.

FAMEs were analyzed by a 7820A GC system (Agilent technologies Inc., Palo Alto, CA, USA) equipped with a FID detector and autosampler. Gas chromatography was performed by a BD-EN14103 capillary column $(30 \mathrm{~m} \times 0.32 \mathrm{~mm} \times 0.25 \mu \mathrm{m})$ using helium as a carrier gas at the velocity of $35 \mathrm{~cm} / \mathrm{s}$. One microliter of sample was injected in split mode (split ratio $1: 20$ ) at $250{ }^{\circ} \mathrm{C}$. The oven temperature program was operated as follows: initial temperature at $50^{\circ} \mathrm{C}$, increasing at $20^{\circ} \mathrm{C} / \mathrm{min}$ to $180^{\circ} \mathrm{C}$ and at $2{ }^{\circ} \mathrm{C} / \mathrm{min}$ from $180{ }^{\circ} \mathrm{C}$ to $230{ }^{\circ} \mathrm{C}$, held isothermally at $230^{\circ} \mathrm{C}$ for $10 \mathrm{~min}$. Data were collected with Agilent EZChrom Elite software. Identification of fatty acids was performed by comparison with 37 FAME standards (Supelco). The results were quantified as relative percentages of the total fatty acids.

\subsection{Computational methods}

HSP was based on the concept that the total cohesive energy density is approximated by the sum of the energy densities required to overcome atomic dispersion forces $\left(\delta_{\mathrm{d}}^{2}\right)$, molecular polar forces arising from dipole moments $\left(\delta_{\mathrm{p}}^{2}\right)$ and hydrogen-bonds (exchange of electrons, proton donor/acceptor) between molecules $\left(\delta_{\mathrm{H}}^{2}\right)$, as given in the following equation.

$\delta_{\text {total }}^{2}=\delta_{\mathrm{d}}^{2}+\delta_{\mathrm{p}}^{2}+\delta_{\mathrm{h}}^{2}$

where $\delta_{\text {total }}$ is the Hansen total solubility parameter, which now consists of three HSP in terms of dispersion $\left(\delta_{\mathrm{d}}\right)$, polar $\left(\delta_{\mathrm{p}}\right)$ and hydrogen-bonding $\left(\delta_{\mathrm{H}}\right)$.

For HSP solvent optimization, the distance of a solvent from the center of the Hansen solubility sphere, $R_{\mathrm{a}}$, has been calculated using Eq. (2) to determine if vegetable oils and VACs are thermodynamically miscible.

$R_{\mathrm{a}}^{2}=4\left(\delta_{\mathrm{d}} A-\delta_{\mathrm{d}} B\right)^{2}+\left(\delta_{\mathrm{p}} A-\delta_{\mathrm{p}} B\right)^{2}+\left(\delta_{\mathrm{h}} A-\delta_{\mathrm{h}} B\right)^{2}$

where $A$ refers to the solute and $B$ refers to the solvent. In general, the parameters follow the classical "like dissolve like" rule that the smaller $R_{\mathrm{a}}$ is, the greater the affinity between solute and solvent. The chemical structures of the solvents and solutes discussed in this article could be mutually transformed by JChemPaint ver. 3.0.1 to their simplified molecular input line entry syntax(SMILES) notations, which were subsequently used to calculate their HSP. These HSP were further modeled to a three-dimensional sphere for better visualizing the solute/solvent interaction (HSPiP Version 4.0, Denmark).

An example molecule with unknown HSPs is triglyceride ${ }^{\mathrm{a}}$, which is illustrated in Fig. 1, 7a. The general chemical structure of 
Version définitive du manuscrit publiée dans / Final version of the manuscript published in :

LWT - Food Science and Technology (2014), 8 p., DOI: 10.1016/j.Iwt.2014.05.064

Journal homepage: www.elsevier.com/locate/lwt<smiles>C=CC(C)(O)CCC=C(C)C</smiles>

1<smiles>CC12CCC(CO1)C2(C)C</smiles>

4<smiles>[R]C(=O)OCC(COC([R])=O)OC([R])=O</smiles>

7<smiles>C=CCc1ccc(OC)cc1</smiles>

2

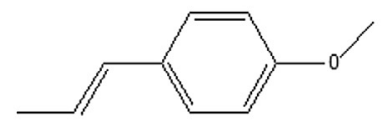

5<smiles>C=CCc1ccc(O)c(OC)c1</smiles><smiles>[131IH]</smiles>

a: $R_{1}$ (Oleic acid), $R_{2}$ (Linoleic acid), $R_{3}$ (Palmatic acid)

b: $R_{1}$ (Oleic acid), $R_{2}$ (Linoleic acid), $R_{3}$ ( $\alpha$-Linolenic acid)

c: $R_{1}$ (Lauric acid), $R_{2}$ (Myristic acid), $R_{3}$ (Palmatic acid)

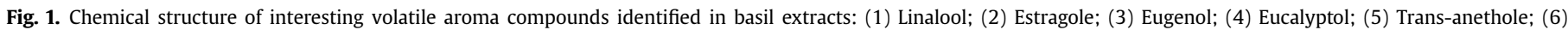
Limonene and vegetable oils: (7) Triglyceride (a) sunflower, olive, grape seed, peanut, avocado, virgin sunflower and olive oil; (b) rapeseed oil; (c) coconut oil; (8) Jojoba oil.

this triglyceride $e^{\mathrm{a}}$ can be transformed to its SMILES notation (CCC $\operatorname{CCCCCCCCCCCCC~}(=0) \mathrm{OCC}(\operatorname{COC}(\operatorname{CCCCCCCC} \backslash \mathrm{C}=\mathrm{C} / \mathrm{CCCCCCC})=\mathrm{O})$ $\mathrm{OC}(\mathrm{CCCCC} / \mathrm{C}=\mathrm{C} \backslash \mathrm{C} / \mathrm{C}=\mathrm{C} \backslash \mathrm{CCCCCCC})=\mathrm{O})$ for further HSP calculation using Yamamoto-Molecular Break (Y-MB) method, which can break SMILES into corresponding functional groups and then estimate its HSP. This method has been embedded in HSPiP software in order to facilitate the direct HSP calculation for other compounds in Fig. 1. The partition coefficient $(\log P)$ of this molecule, which is difficult to found in standard databases, can be also predicted using Y-MB method with its SMILES.

\subsection{Solid-liquid extraction}

The solid-liquid ratio (15\%) used in macerations was referred to the previous studies (Achat et al., 2012; Veillet, Tomao, \& Chemat, 2010). A preliminary kinetic study was firstly performed at $37^{\circ} \mathrm{C}$ for determining the optimal time for the rest of treatments. The enriched sunflower oil samples collected at different time intervals ( $30 \mathrm{~min}, 1 \mathrm{~h}, 2 \mathrm{~h}, 3 \mathrm{~h}, 4 \mathrm{~h}, 5 \mathrm{~h}$ and $6 \mathrm{~h}$ ) were immediately transferred into sealed vials for HS-SPME/GC-MS quantification. Linalool as the reference VAC has been traced and the 4-h maceration was finally determined for the further investigations because of the highest linalool concentration it achieved.

Dried basils were mechanically ground and sieved to $0.25 \mathrm{~mm}$ particle size. The fine basil powders were then divided into two portions, one (3.75 g) was performed in 4-h maceration using $25 \mathrm{~mL}$ of dichloromethane. During the maceration, the solid residue was filtered in vacuum and re-extracted with fresh dichloromethane under the same condition. The organic extracts were used in GC-MS analysis afterward for identification of main VACs in basil. The another ( $3.75 \mathrm{~g}$ ) was poured into flasks containing $25 \mathrm{~mL}$ of various vegetable oils on an RT-10 magnetic stirrer plate (IKAMAG, Germany) over $4 \mathrm{~h}$ in a temperature-controlled chamber. All samples were then centrifuged in Sigma 4-16k refrigerated centrifuge at $2739 \mathrm{~g}$ for $15 \mathrm{~min}$ at $25^{\circ} \mathrm{C}$ and $4 \mathrm{~g}$ of the supernatants were transferred for the HS-SPME/GC-MS analysis. All experiments were carried out in triplicates.

\subsection{Headspace volatile analysis}

Due to the relatively high viscosity of lipid medium, a timesaving HS-SPME/GC-MS was applied to give a direct and effective analysis for VACs' identification and quantification in oily basil extracts. It was carried out using a GC/MS-QP2010 (Shimadzu, Kyoto, Japan) equipped with an AOC 5000 auto-injector (Shimadzu, Kyoto, Japan). The auto sampler was operated in SPME mode using a divinylbenzene-carboxen-polydimethylsiloxane fiber $(2 \mathrm{~cm}, 23-$ gauge, 50/30 $\mu \mathrm{m}$ DVB/CAR/PDMS; Supelco, Bellefonte, PA, USA) for extraction. For each extraction, $4 \mathrm{~g}$ of oily extract was hermetically sealed in $20 \mathrm{~mL}$ vials with $18 \mathrm{~mm}$ magnetic universal screw cap containing aluminum seals and PTFE/silicone septa (Grace, France). The samples were equilibrated during incubation time at $35^{\circ} \mathrm{C}$ for $15 \mathrm{~min}$. The SPME device was then automatically inserted into the sealed vial through the septum, and the fiber was exposed to the sample headspace at the same temperature for $25 \mathrm{~min}$. The oils had been agitated during the incubation and extraction procedures. Subsequently, the SPME fiber was removed and inserted into the injector port of the GC-MS for desorption at $250{ }^{\circ} \mathrm{C}$ for $5 \mathrm{~min}$.

The GC-MS analysis was performed on a QP2010 (Shimadzu, Japan) equipped with a capillary column UB-WAX $(30 \mathrm{~m} \times 0.25 \mathrm{~mm} \times 0.5 \mu \mathrm{m})$. Helium was used as a carrier gas at the constant flow of $35 \mathrm{~cm} / \mathrm{s}$. The separation was performed using the following temperature program: initial oven temperature $35^{\circ} \mathrm{C}$ hold for $2 \mathrm{~min}$, then rose at $5^{\circ} \mathrm{C} / \mathrm{min}$ until $230^{\circ} \mathrm{C}$. The temperature of the transfer line connecting the GC and MS was held at $250{ }^{\circ} \mathrm{C}$. The inlet was operated in the splitless mode and the mass spectrometer operated in the electron impact mode at $70 \mathrm{eV}$ with continuous scans (every $0.2 \mathrm{~s}$ ) over the mass to charge ratio $(\mathrm{m} / \mathrm{z}$ ) 
Version définitive du manuscrit publiée dans / Final version of the manuscript published in :

LWT - Food Science and Technology (2014), 8 p., DOI: 10.1016/j.Iwt.2014.05.064

Journal homepage: www.elsevier.com/locate/lwt

Table 1

Major composition of vegetable oils identified by fatty acid methyl ester analysis.

\begin{tabular}{|c|c|c|c|c|c|c|c|c|c|c|}
\hline \multirow[t]{2}{*}{ Main fatty acid composition(wt \%) ${ }^{\mathrm{a}}$} & \multicolumn{10}{|l|}{ Oil names } \\
\hline & Virgin sunflower & Coconut & Peanut & Rapeseed & Sunflower & Olive & Grape seed & Virgin olive & Avocado & Jojoba \\
\hline Lauric acid (C12:0) & & 43.2 & & & & & & & & \\
\hline Myristic acid (C14:0) & & 17.6 & & & & & & & & \\
\hline Palmitic acid (C16:0) & 5.9 & 9.3 & 6.0 & & 4.4 & 10.5 & 6.0 & 18.3 & 15.7 & \\
\hline Oleic acid (C18:1) & 24.0 & & 73.2 & 62.5 & 55.5 & 79.8 & 14.4 & 57.2 & 67.3 & \\
\hline Linoleic acid (C18:2) & 64.3 & & 11.9 & 19.8 & 35.3 & 4.2 & 75.6 & 18.1 & 10.7 & \\
\hline$\alpha$-Linolenic acid (C18:3) & & & & 9.6 & & & & & & \\
\hline Eicosenoic acid (C20:1) & & & & & & & & & & 60.2 \\
\hline Erucic acid (C22:1) & & & & & & & & & & 33.0 \\
\hline
\end{tabular}

${ }^{\mathrm{a}}$ Fatty acids which have not been used for HSP predictions are not mentioned in this table.

from 35 to 250. Data were collected with GC-MS Solution software. The major VACs were identified by comparison of their retention index and their mass spectra with those of authentic standards or using the NIST'98 [US National Institute of Standards and Technology (NIST), Gaithersburg, MD, USA] mass spectral database. Each VAC was replicated six times for this HS-SPME/GC-MS analysis.

\subsection{Statistical analysis}

As the one-way ANOVA results showed that ten vegetable oils have a statistically significant difference $(P<0.05)$ on the solubility of each VAC at the 95\% confidence level, mean values were further transformed using MATLAB 2013a (The MathWorks, Inc. Natick, Massachusetts, USA). Firstly, a principal component analysis (PCA) was performed to reduce the dimensionality of our data set (individuals: vegetable oils; variables: VACs) by linear combination into new coordinate systems which are completely uncorrelated with each other. The mean concentrations in ten oily extracts were taken for the determination of principal components so as to compare the solubility of ten vegetable oils in a two-dimensional graph. Subsequently, an agglomerative hierarchical clustering (AHC) was applied to classify the closest individuals into clusters according to an aggregation criterion. The Ward's hierarchical clustering was used to calculate dissimilarities from the Euclidean distances and aggregation criterion corresponding to the minimization of the within-cluster inertia and the maximization of between-cluster inertia. This method led to a partition of vegetable oils into homogenous clusters (low within-variability) in terms of concentrations of six VACs extracted, which are different from others with a high between-variability. A dendrogram was finally obtained to illustrate the aggregations made at each successive stage of the analysis (Fréville, Hecke, Marinkovic, Ernenwein, \& Pezron, 2011).

Table 2

Predicted Hansen solubility parameters and partition coefficient $(\log P$ ) of solvents and solutes.

\begin{tabular}{llllll}
\hline Compounds & $\delta_{\mathrm{d}}\left(\mathrm{MPa}^{1 / 2}\right)$ & $\delta_{\mathrm{p}}\left(\mathrm{MPa}^{1 / 2}\right)$ & $\delta_{\mathrm{H}}\left(\mathrm{MPa}^{1 / 2}\right)$ & $\delta_{\text {total }}\left(\mathrm{MPa}^{1 / 2}\right)$ & $\log P$ \\
\hline Limonene & 16.8 & 1.9 & 3.4 & 17.2 & 4.4 \\
Eucalyptol & 17 & 4 & 3.3 & 17.8 & 3.2 \\
Linalool & 16.5 & 2.8 & 6.9 & 18.1 & 3.0 \\
Estragole & 18 & 4.6 & 4.9 & 19.2 & 3.1 \\
Trans-anethole & 18.4 & 4.6 & 5.2 & 19.7 & 3.1 \\
Eugenol & 18.5 & 5.6 & 9 & 20.7 & 2.6 \\
Dichloromethane & 17 & 7.3 & 7.1 & 19.8 & 1.0 \\
Triglyceride & 16.1 & 3.8 & 3.1 & 16.8 & 21.4 \\
Rapeseed oil & 15.8 & 4.7 & 4.2 & 17.0 & 21.8 \\
Coconut oil & 16.7 & 2.8 & 6.2 & 18.0 & 17.5 \\
Jojoba oil & 16.8 & 1.3 & 2 & 17.0 & 17.4 \\
\hline
\end{tabular}

\footnotetext{
a Sunflower, olive, grape seed, peanut, avocado, virgin sunflower and olive oil.
}

\section{Result and discussion}

\subsection{The composition of vegetable oils}

The major fatty acids determined in vegetable oils were selected to constitute the structure of triglycerides for further HSP calculation. As the result of origin, quality and process, the results showed that the composition of vegetable oils was very variable and complex (Table 1). Most of vegetable oils (virgin sunflower, sunflower, virgin olive, olive, grape seed, peanut and avocado oil) presented
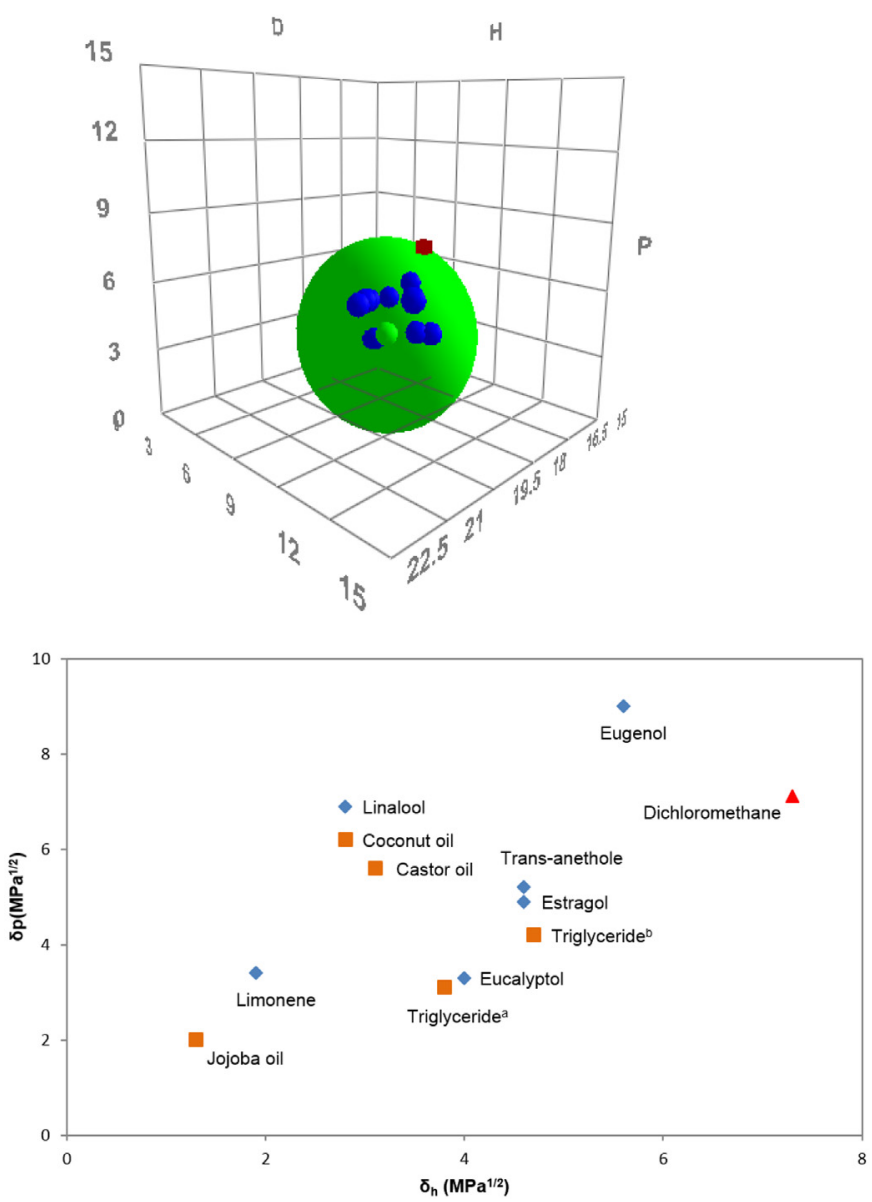

Fig. 2. General three-dimensional Hansen solubility sphere (blue dots: vegetable oils and volatile aroma compounds; red cubes: dichloromethane) and two-dimensional diagram ( $\boldsymbol{\square}$ vegetable oils and $\boldsymbol{\Delta}$ dichloromethane) and solutes ( volatile aroma compounds). (For interpretation of the references to color in this figure legend, the reader is referred to the web version of this article.) 
Version définitive du manuscrit publiée dans / Final version of the manuscript published in :

LWT - Food Science and Technology (2014), 8 p., DOI: 10.1016/j.Iwt.2014.05.064

Journal homepage: www.elsevier.com/locate/lwt

the same main fatty acid composition (linoleic acid, oleic acid and palmitic acid) but with different proportions. The main fatty acids of rapeseed oil were oleic, linoleic and $\alpha$-linolenic acid. The coconut contained $91 \%$ of saturated fatty acids, which the three main fatty acids were lauric, myristic and palmitic acid. Jojoba oil was a liquid wax which had a long fatty acid chain that mainly composed of eicosenoic and erucic acid.
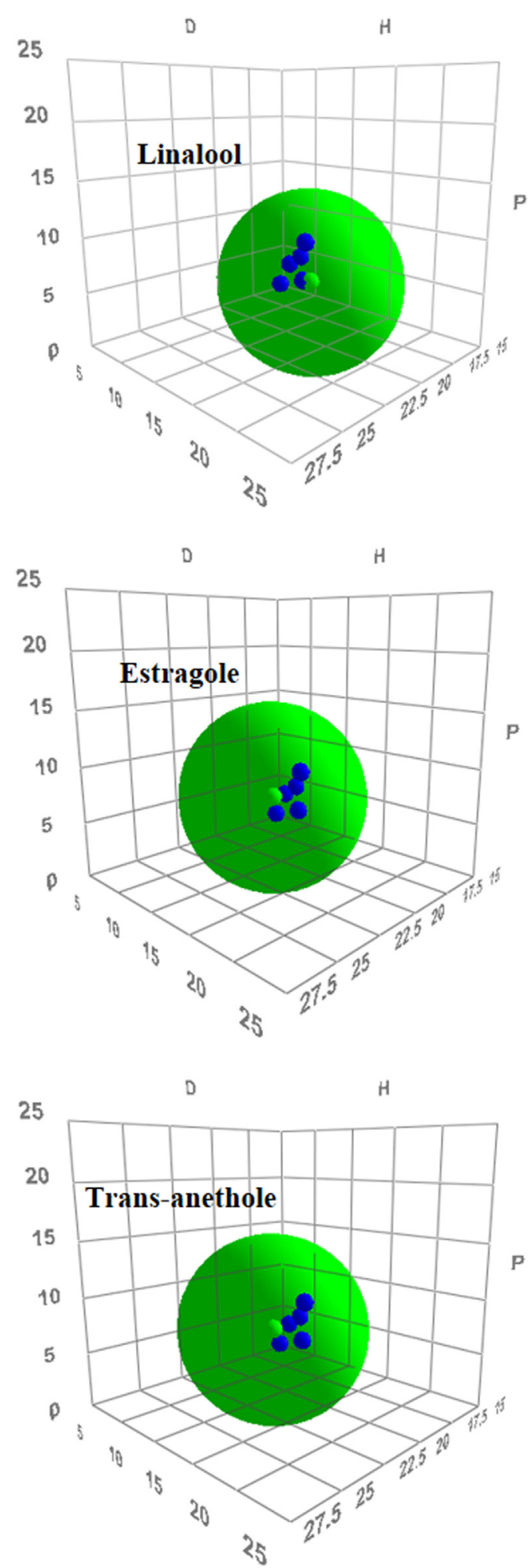

\subsection{The composition of basil}

The VACs in organic basil extracts were identified by GC-MS using liquid injection of $1.0 \mu \mathrm{L}$ extracts, which was then quantified by GC-FID. The three main VACs in basil were linalool (30.18\%), Eugenol (14.97\%) and Estragole (12.91\%). In addition, other VACs such as eucalyptol (5.46\%), trans-anethole (2.06\%) and limonene
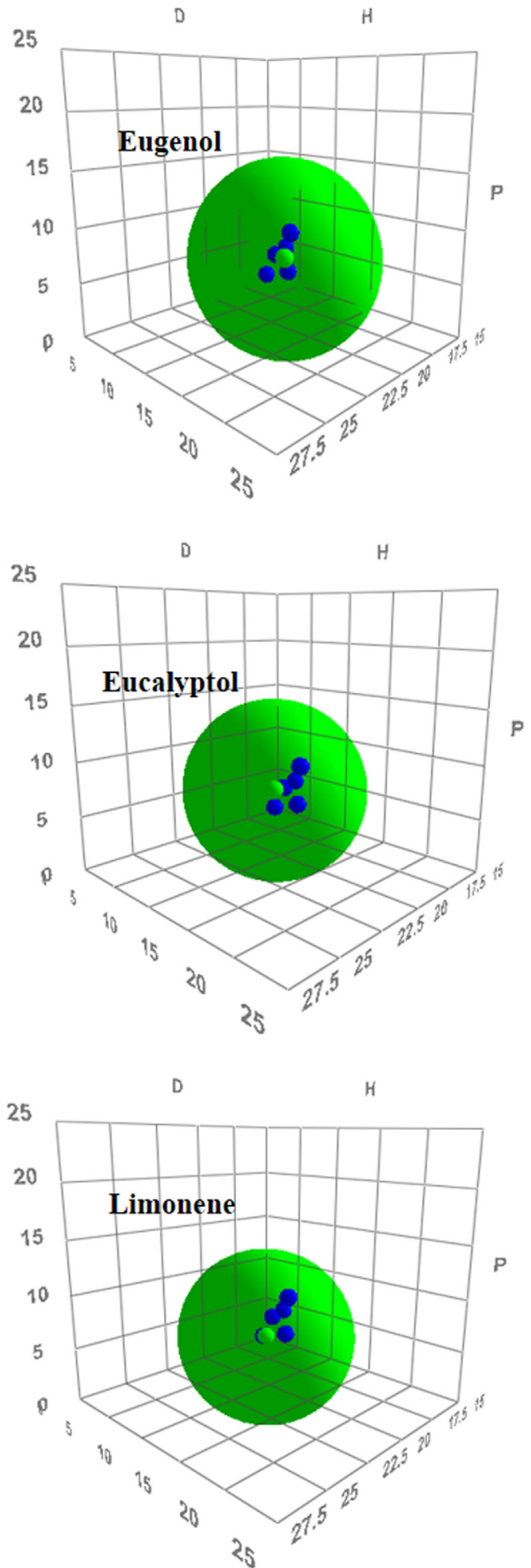

Fig. 3. Three dimensional Hansen solubility sphere of all solvents for each volatile aroma compound. 
(0.18\%), have represented with a lower proportion than previously published values (Klimankova et al., 2008; Veillet et al., 2010). This may due to the cultivar, the growing conditions or even to the seasonal variations (Hussain, Anwar, Sherazi, \& Przybylski, 2008). These six interesting VACs were selected and traced purposefully in the following extractions using vegetable oils as solvents.

\subsection{Theoretical solubility in vegetable oils}

Since HSP are available for limited numbers of solvents, it is interesting to introduce methods for predicting non-standard solvents only through their chemical structures. Although there are several options for HSP prediction, Yamamoto-Molecular Break (YMB) method shows its superiority for calculation of molecules with a long chain and high molecule weight due to its stability and high accuracy comparing to other HSP estimation methods. Moreover, other physiochemical properties can be also evaluated with this proposed method which other methods cannot achieve.

The HSP of solvents and solutes were calculated from their structures as presented in Table 2 were used in plotting a 3D HSP sphere for theoretical characterization of the volatile-vegetable oil interaction. In this general 3D diagram, the green dot in the sphere center is the theoretical optimum HSP for good solvency. Blue dots located inside the sphere are generally considered good solvents while red cubes present the solvents that have relatively poor solubility (Fig. 2). All solvents and VACs in blue were closer to the HSP center than dichloromethane in red, which means vegetable oils have the potency of being alternatives to dichloromethane for dissolving VACs. The 2D graph of $\delta_{\mathrm{p}}$ versus $\delta_{\mathrm{H}}$ indicated this as well with close HSP values between VACs and oils. Moreover, the calculated $\delta_{\text {total }}$ value of VACs $\left(18.78 \pm 1.03 \mathrm{MPa}^{1 / 2}\right)$ also confirmed that they are closely related to that of vegetable oils $\left(17.36 \pm 0.58 \mathrm{MPa}^{1 / 2}\right)$, classifying the VAC-oil mixture as non-polar fraction though eugenol had relatively high $\delta_{\mathrm{H}}$ value due to its hydroxyl. The HSPs of all solvents were then modeled for each VAC so that the vegetable oil with relatively small $R_{\mathrm{a}}$ can be theoretically determined as the optimal solvent taking experimental results into account. Fig. 3 showed that all solvents were close to the desired VACs as HSP centers, which could be considered as good solvents including dichloromethane. With an overall $R_{\mathrm{a}}$ consideration of solvents for all VACs in Table 3, it is interesting to notice that the vegetable oils showed their potential to replace dichloromethane even though their theoretical solubility are variable.

In addition, the $\log P$ of all solvents and solutes has been theoretically predicted as well since VACs are often characterized in flavor physical chemistry by their partition coefficient, (Table 2). The predictive values of VACs were similar to that in the standard database and non-standard oil solvents showed high values of $\log P$ corresponding to their lipophilicity. In contrast, more polar dichloromethane showed a much lower $\log P$ value. The accuracy of $\log P$ values has also demonstrated the power of the Y-MB method in HSP predictions.

\subsection{Experimental solubility in vegetable oils}

The six standards of VACs at different concentrations have been analyzed in different aromatized oils under the same HS-SPME/ GC-MS condition at first in order to test the effects of oily matrix and HS-SPME fiber. It is important to note that the successive fiber injections will be exhausted and aged in aromatized oils which may bring lots of variability. Given this reason, the fiber used has been kept consistent and updated for analyses of each independent aromatized oil so that the error quantification could be minimized. The one-way ANOVA result indicated that the oily matrix and fiber effect was insignificant so that calibration curves obtained for each
VAC were available for all vegetable oils. Six external standards of VACs at the same concentration gradients $(\times 2, \times 4, \times 8)$ were prepared in any of vegetable oils, which have further been analyzed by HS-SPME/GC-MS so as to obtain calibration curves for each VAC. The external standard concentrations used for mother solution preparation are $600 \mathrm{mg} / \mathrm{L}$ for linalool, $250 \mathrm{mg} / \mathrm{L}$ for eugenol and eucalyptol, $50 \mathrm{mg} / \mathrm{L}$ for estragole, $30 \mathrm{mg} / \mathrm{L}$ for anethole and $20 \mathrm{mg} / \mathrm{L}$ for limonene. The calibration curves and the concentrations of VACs in aromatized oils were exhibited in Table 4.

The PCA has plotted all solvents into a 2D plot representing PC2 versus PC1 (Fig. 4). Generally, the variability of the independent principal components is the percentage of information which is well represented on other components. In this case, the main components PC1 (73.85\%) and PC2 (15\%) lead together to represent for nearly $90 \%$ of the original information with about $10 \%$ loss of information. The distribution of ten vegetable oils on the PCA plots well described their inner similarity depending on the solubility of VACs inside. This is directly related to independent variables (PC1 and PC2) which can bring significant information for the oil solvent discrimination. The following AHC has been carried out on the basis of the concentration of all VACs as well (Fig. 5). The dendrogram showed that the dissolving power of vegetable oil solvents could be classified into three different clusters, which further confirmed the observations of PCA. The cluster 1, which is composed of coconut, sunflower, olive, rapeseed and grape seed oil, showed the highest dissimilarity to other two clusters. This indicates that the dissolving power of vegetable oils in this cluster is very different from those in other clusters. The vegetable oils merging together within each cluster showed low dissimilarity on the dissolving power. Therefore, the low dissimilarity was found in cluster 1 among rapeseed, olive and grape seed oil. However, coconut and sunflower oil presented high dissimilarity corresponding to their higher dissolving power of all VACs than others. These results were generally in good consistency with theoretical HSP results. For the sake of high nutritional value and economically viable, sunflower oil can be decided as the optimal vegetable oil solvent for extraction of VACs from basil. It is interesting to find that vegetable oils having similar Triglyceride ${ }^{a}$ are distributed in three different clusters due to their complex compositions. For instance, the refined oils in cluster 1 with higher dissolving power are more pure and non-polar than virgin oils in cluster 2 because of the removal of minor compounds during the refining process. However, avocado oil having a typically high unsaponifiable content leads to a lower solubility. Meanwhile,

Table 3

Theoretical distance of solvents to each volatile aroma compound as the center of Hansen solubility sphere.

\begin{tabular}{|c|c|c|c|c|c|}
\hline \multicolumn{2}{|l|}{ Linalool } & \multicolumn{2}{|l|}{ Eugenol } & \multicolumn{2}{|l|}{ Estragole } \\
\hline Solvent & $R_{\mathrm{a}}$ & Solvent & $R_{\mathrm{a}}$ & Solvent & $R_{\mathrm{a}}$ \\
\hline Coconut oil & 0.8 & $\mathrm{CH}_{2} \mathrm{Cl}_{2}$ & 3.9 & Coconut oil & 3.4 \\
\hline Rapeseed oil & 3.6 & Coconut oil & 5.4 & $\mathrm{CH}_{2} \mathrm{Cl}_{2}$ & 4.0 \\
\hline Triglyceride ${ }^{a}$ & 4.0 & Rapeseed oil & 7.3 & Triglyceride $^{a}$ & 4.3 \\
\hline $\mathrm{CH}_{2} \mathrm{Cl}_{2}$ & 4.6 & Triglyceride $^{a}$ & 7.8 & Rapeseed oil & 4.5 \\
\hline Jojoba oil & 5.1 & Jojoba oil & 8.9 & Jojoba oil & 5.6 \\
\hline \multicolumn{2}{|l|}{ Eucalyptol } & \multicolumn{2}{|c|}{ Trans-anethole } & \multicolumn{2}{|l|}{ Limonene } \\
\hline Solvent & $R_{\mathrm{a}}$ & Solvent & $R_{\mathrm{a}}$ & Solvent & $R_{\mathrm{a}}$ \\
\hline Triglyceride $^{\mathrm{a}}$ & 1.8 & Coconut oil & 4.0 & Jojoba oil & 1.8 \\
\hline Rapeseed oil & 2.6 & $\mathrm{CH}_{2} \mathrm{Cl}_{2}$ & 4.3 & Triglyceride $^{a}$ & 2.4 \\
\hline Jojoba oil & 3.1 & Triglyceride $^{a}$ & 5.1 & Coconut oil & 2.9 \\
\hline Coconut oil & 3.3 & Rapeseed oil & 5.3 & Rapeseed oil & 3.5 \\
\hline $\mathrm{CH}_{2} \mathrm{Cl}_{2}$ & 5.0 & Jojoba oil & 6.2 & $\mathrm{CH}_{2} \mathrm{Cl}_{2}$ & 6.6 \\
\hline
\end{tabular}

$R_{\mathrm{a}}$ : the distance of solvents from the fixed HSP center (volatile aroma compounds) a Sunflower, olive, grape seed, peanut, avocado, virgin sunflower and olive oil. 
Version définitive du manuscrit publiée dans / Final version of the manuscript published in :

LWT - Food Science and Technology (2014), 8 p., DOI: 10.1016/j.Iwt.2014.05.064

Journal homepage: www.elsevier.com/locate/lwt

Table 4

Calibration curves and calculated concentration of each volatile aroma compound in aromatized vegetable oils.

\begin{tabular}{|c|c|c|c|c|c|}
\hline \multicolumn{3}{|l|}{ Linalool } & \multicolumn{3}{|l|}{ Eugenol } \\
\hline \multicolumn{3}{|c|}{$y=7.61 \times 10^{-6} x-20.6 \quad R^{2}=0.99$} & \multicolumn{3}{|c|}{$y=6.77 \times 10^{-5} x-14.2 \quad R^{2}=0.98$} \\
\hline & Mean $\pm \mathrm{SD}^{\mathrm{a}}$ & $\begin{array}{l}\text { RSD } \\
(\%)\end{array}$ & & Mean $\pm \mathrm{SD}^{\mathrm{a}}$ & $\begin{array}{l}\text { RSD } \\
(\%)\end{array}$ \\
\hline Avocado oil & $224.20 \pm 39.92$ & 17.5 & Avocado oil & $128.92 \pm 25.56$ & 19.8 \\
\hline Peanut oil & $374.55 \pm 50.72$ & 13.5 & Peanut oil & $130.40 \pm 14.81$ & 11.4 \\
\hline Jojoba oil & $376.52 \pm 10.66$ & 2.8 & Virgin olive oil & $165.87 \pm 29.52$ & 17.8 \\
\hline Virgin olive oil & $389.64 \pm 48.03$ & 12.3 & $\begin{array}{l}\text { Virgin } \\
\text { sunflower oil }\end{array}$ & $166.57 \pm 22.05$ & 13.2 \\
\hline $\begin{array}{l}\text { Virgin } \\
\quad \text { sunflower oil }\end{array}$ & $471.96 \pm 46.71$ & 9.9 & Rapeseed oil & $179.09 \pm 23.91$ & 13.4 \\
\hline Grape seed oil & $496.53 \pm 72.11$ & 14.5 & Grape seed oil & $180.36 \pm 21.24$ & 11.8 \\
\hline Olive oil & $510.36 \pm 45.41$ & 11.0 & Coconut oil & $182.26 \pm 32.75$ & 18.0 \\
\hline Coconut oil & $512.71 \pm 97.89$ & 19.1 & Jojoba oil & $183.24 \pm 26.91$ & 14.7 \\
\hline Rapeseed oil & $520.06 \pm 64.86$ & 12.4 & Olive oil & $190.03 \pm 25.32$ & 13.3 \\
\hline Sunflower oil & $551.80 \pm 87.43$ & 15.8 & Sunflower oil & $200.09 \pm 26.26$ & 13.1 \\
\hline
\end{tabular}

\begin{tabular}{|c|c|c|c|c|c|}
\hline \multicolumn{3}{|l|}{ Estragole } & \multicolumn{3}{|l|}{ Eucalyptol } \\
\hline \multicolumn{3}{|c|}{$y=9.27 \times 10^{-6} x-5.58 \quad R^{2}=0.99$} & \multicolumn{3}{|c|}{$y=1.41 \times 10^{-6} x-3.05 \quad R^{2}=0.99$} \\
\hline & Mean $\pm \mathrm{SD}^{\mathrm{a}}$ & $\begin{array}{l}\text { RSD } \\
(\%)\end{array}$ & & Mean $\pm S^{a}$ & RSD (\%) \\
\hline Avocado oil & $99.12 \pm 20.74$ & 20.9 & Avocado oil & $23.40 \pm 4.68$ & 20.0 \\
\hline Peanut oil & $107.65 \pm 16.59$ & 15.4 & Virgin olive oil & $23.56 \pm 3.62$ & 15.3 \\
\hline Jojoba oil & $112.45 \pm 1.93$ & 1.7 & Jojoba oil & $24.16 \pm 1.35$ & 5.6 \\
\hline Virgin olive oil & $121.55 \pm 20.23$ & 16.6 & $\begin{array}{l}\text { Virgin } \\
\text { sunflower oil }\end{array}$ & $25.57 \pm 2.98$ & 11.7 \\
\hline $\begin{array}{l}\text { Virgin } \\
\quad \text { sunflower oil }\end{array}$ & $150.15 \pm 19.27$ & 12.8 & Peanut oil & $34.76 \pm 2.01$ & 5.8 \\
\hline Rapeseed oil & $155.44 \pm 25.69$ & 16.7 & Rapeseed oil & $34.98 \pm 1.91$ & 5.5 \\
\hline Olive oil & $156.00 \pm 23.47$ & 15.0 & Coconut oil & $40.20 \pm 4.83$ & 12.0 \\
\hline Grape seed oil & $175.99 \pm 29.51$ & 16.8 & Olive oil & $41.26 \pm 1.81$ & 4.4 \\
\hline Sunflower oil & $177.16 \pm 28.95$ & 16.3 & Grape seed oil & $45.46 \pm 8.23$ & 18.1 \\
\hline Coconut oil & $207.22 \pm 40.54$ & 19.6 & Sunflower oil & $46.24 \pm 6.36$ & 13.8 \\
\hline
\end{tabular}

\begin{tabular}{|c|c|c|c|c|c|}
\hline \multicolumn{3}{|l|}{ Trans-anethole } & \multicolumn{3}{|l|}{ Limonene } \\
\hline \multicolumn{3}{|c|}{$y=1.94 \times 10^{-5} x-20.5 \quad R^{2}=0.98$} & \multicolumn{3}{|c|}{$y=1.41 \times 10^{-6} x-0.174 \quad R^{2}=0.99$} \\
\hline & Mean $\pm \mathrm{SD}^{\mathrm{a}}$ & $\begin{array}{l}\text { RSD } \\
(\%)\end{array}$ & & Mean $\pm S^{a}$ & RSD (\%) \\
\hline Peanut oil & $5.67 \pm 0.68$ & 11.9 & Virgin olive oil & $2.44 \pm 0.30$ & 12.1 \\
\hline Avocado oil & $7.26 \pm 1.22$ & 16.8 & $\begin{array}{l}\text { Virgin } \\
\text { sunflower oil }\end{array}$ & $3.43 \pm 0.27$ & 7.9 \\
\hline Virgin olive oil & $10.67 \pm 1.97$ & 18.5 & Jojoba oil & $3.84 \pm 0.27$ & 7.1 \\
\hline Jojoba oil & $10.87 \pm 1.69$ & 15.6 & Coconut oil & $4.55 \pm 0.66$ & 14.5 \\
\hline Virgin sunflower oil & $14.78 \pm 1.98$ & 13.4 & Peanut oil & $6.07 \pm 0.88$ & 14.6 \\
\hline Rapeseed oil & $15.59 \pm 1.80$ & 11.5 & Avocado oil & $6.93 \pm 1.25$ & 18.0 \\
\hline Olive oil & $16.31 \pm 3.03$ & 18.6 & Olive oil & $7.91 \pm 0.56$ & 7.0 \\
\hline Grape seed oil & $18.18 \pm 3.10$ & 17.1 & Grape seed oil & $11.51 \pm 1.60$ & 13.9 \\
\hline Sunflower oil & $20.32 \pm 2.75$ & 13.5 & Rapeseed oil & $11.97 \pm 1.51$ & 12.6 \\
\hline Coconut oil & $23.85 \pm 1.90$ & 8.0 & Sunflower oil & $15.14 \pm 1.58$ & 10.4 \\
\hline
\end{tabular}

${ }^{\mathrm{a}} \mathrm{mg} / \mathrm{L}$ of solvent.

it is also important to note that the HSP prediction is based on the thermodynamics rather than kinetics. The HSP value can only predict the dissolution possibility of molecules but will not affect the diffusion and final extraction yield. As a consequence, it is reasonable to have slight divergences between experimental and theoretical results, which have insignificant influence on the comparison and selection of solvents for extractions of VACs. Moreover, the limited predicted HSP values arising from the complex composition of vegetable oil triglycerides should be developed.

Since the vegetable oils have been used as substitutes to dichloromethane in the extraction of VACs, a novel extraction process has been set up to bring about benefits correspond to the

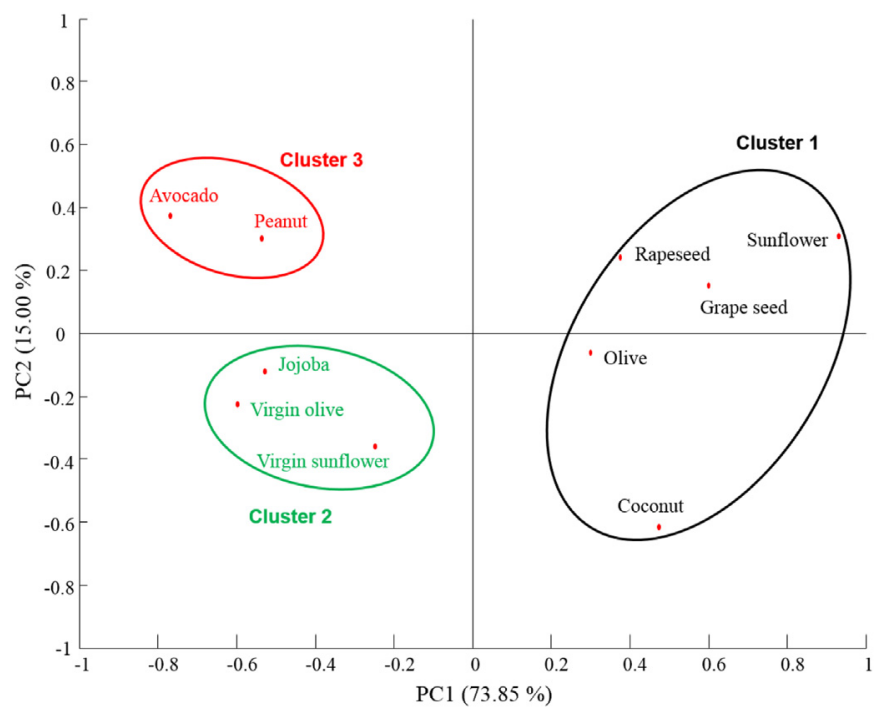

Fig. 4. Dissolving power of vegetable oils in the principal component analytical plots corresponding to six main volatile aroma compounds extracted.

six principles of green extraction (Chemat, Abert-Vian, \& Cravotto, 2012). The integration of appropriate techniques can not only improve the extraction efficiency and save energy, but also prevent lipid oxidation or contamination because of the short extraction time (Achat et al., 2012; Japon-Lujan, Janeiro, \& Luque de Castro, 2008). Besides, vegetable oils extracted using green solvents (e.g. $\rho$ cymene) showed potential of achieving a truly green extraction process for future industrial applications than analytical applications in the laboratory (Li et al., 2014).

\section{Conclusions}

Vegetable oils, sunflower oil in particular, has been theoretically and experimentally proven as a preferential solvent in this work, which can be safely used in conventional extraction of VACs from

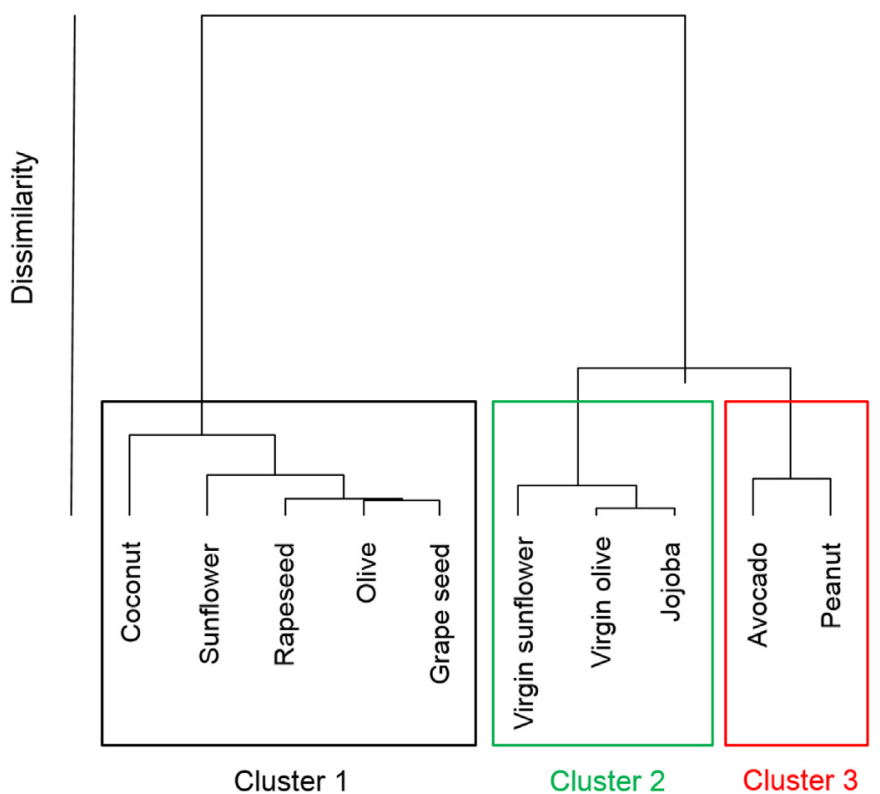

Fig. 5. Dendrogram resulting from Ward's hierarchical cluster analysis based on the dissolving power of vegetable oils in terms of six volatile aroma compounds extracted. 


\section{Version définitive du manuscrit publiée dans / Final version of the manuscript published in : \\ LWT - Food Science and Technology (2014), 8 p., DOI: 10.1016/j.Iwt.2014.05.064 \\ Journal homepage: www.elsevier.com/locate/lwt}

dried basil with a considerable yield. Although dichloromethane cannot stand for all petroleum-based solvents, this preliminary study inspires a green solution for agri-food industry, in which aromatized oils as novel food products do not need any separation steps after extractions. Besides, coupling the Hansen's method to experimental solubility profile was found to be good in evaluating single-used solvents' properties even it has some defects in complex multi-component systems. However, these drawbacks have insignificant effects on the availability of using HSPs as heuristic values for solvent comparison and selection.

\section{References}

Achat, S., Tomao, V., Madani, K., Chibane, M., Elmaataoui, M., Dangles, O., et al. (2012). Direct enrichment of olive oil in oleuropein by ultrasound-assisted maceration at laboratory and pilot plant scale. Ultrasonics Sonochemistry, 19, $777-786$.

Antoun, N., \& Tsimidou, M. (1997). Gourmet olive oils: stability and consumer acceptability studies. Food Research International, 30, 131-136.

Bagamboula, C. F., Uyttendaele, M., \& Debevere, J. (2004). Inhibitory effect of thyme and basil essential oils, carvacrol, thymol, estragole, linalool and pcymene towards Shigella sonnei and S. flexneri. Food Microbiology, 21, 33-42.

Baratta, M. T., Dorman, H. J. D., Deans, S. G., Figueiredo, A. C., Barroso, J. G., \& Ruberto, G. (1998). Antimicrobial and antioxidant properties of some commercial essential oils. Flavour and Fragrance Journal, 13, 235-244.

Bousbia, N., Abert-Vian, M., Ferhat, M. A., Petitcolas, E., Meklati, B. Y., \& Chemat, F. (2009). Comparison of two isolation methods for essential oil from rosemary leaves: hydrodistillation and microwave hydrodiffusion and gravity. Food Chemistry, 114, 355-362.

Chalchat, J. C., \& Ozcan, M. M. (2008). Comparative essential oil composition of flowers, leaves and stems of basil (Ocimum basilicum L.) used as herb. Food Chemistry, 110, 501-503.

Chemat, F., Abert-Vian, M., \& Cravotto, G. (2012). Green extraction of natural products: concept and principles. International Journal of Molecular Sciences, 13, 8615-8627.

Chevereau, P. (1998). Method for extracting and fixing aromas on non-aqueous substrate, machine for implementing the method, and product thereby. U.S. patent 5853726

Daood, H. G., Illés, V., Gnayfeed, M. H., Mészáros, B., Horváth, G., \& Biacs, P. A. (2002). Extraction of pungent spice paprika by supercritical carbon dioxide and subcritical propane. The Journal of Supercritical Fluids, 23, 143-152.

De Felice, M., De Leonardis, T., \& Comes, S. (1993). Aromatizzazione degli oli alimentari. Effetti sull' autossidazione. Industrie Alimentai, 3, 249-253.

Fréville, V., Hecke, E. V., Marinkovic, S., Ernenwein, C., \& Pezron, I. (2011). Mapping and multivariate analysis for a rapid evaluation of new green solvents characteristics and efficiency. Journal of Dispersion Science and Technology, 32, $1742-1752$.

Gambacorta, G, Faccia, M. Pati, S, Lamacchia, C, Baiano, A \& La Notte, E (2007). Changes in the chemical and sensorial profile of extra virgin olive oils flavored with herbs and spices during storage. Journal of Food Lipids, 14, 202-215.

Gouveia, A. F., Duarte, C., Beirão-da-Costa, M. L., Bernardo-Gil, M. G., \& MoldãoMartins, M. (2006). Oxidative stability of olive oil flavoured by Capsicum frutescens supercritical fluid extracts. European Journal of Lipid Science and Technology, 108, 421-428.

Hamed, S. F. (2007). Edible oil as an alternative solvent for extraction of antioxidant components from natural herbs. Journal of Applied Science Research, 2, 567-571.

Hansen, C. M. (2000). Solubility parameters-an introduction. In Hansen solubility parameters: A user's handbook (pp. 1-25). Florida: CRS Press LLC.
Hussain, A. I., Anwar, F., Sherazi, S. T. H., \& Przybylski, R. (2008). Chemical composition, antioxidant and antimicrobial activities of basil essential oils depends on seasonal variations. Food Chemistry, 108, 986-995.

Japon-Lujan, R., Janeiro, P., \& Luque de Castro, M. D. (2008). Solid-liquid transfer of biophenols from olive leaves for the enrichment of edible oils by a dynamic ultrasound-assisted approach. Journal of Agricultural and Food Chemistry, 56, $7231-7235$

Kang, C. D., \& Sim, S. J. (2008). Direct extraction of astaxanthin from Haematococcus culture using vegetable oils. Biotechnology Letters, 30, 441-444.

Klimankova, E., Holadova, K., Hajslova, J., Cajka, T., Poutka, J., \& Koudela, M. (2008) Aroma profiles of five basil (Ocinum basilicum L.) cultivars grown under conventional and organic conditions. Food Chemistry, 107, 464-472.

Lee, S. J., Umano, K., Shibamoto, T., \& Lee, K. G. (2005). Identification of volatile components in basil (Ocimum basilicum L.) and thyme leaves (Thymus vulgaris L.) and their antioxidant properties. Food Chemistry, 91, 131-137.

Li, Y., Fabiano-Tixier, A. S., Tomao, V., Cravotto, G., \& Chemat, F. (2013). Green ultrasound-assisted extraction of carotenoids based on the bio-refinery concept using sunflower oil as an alternative solvent. Ultrasonics Sonochemistry, 20, $12-18$.

Li, Y., Fine, F., Fabiano-Tixier, A. S., Abert-Vian, M., Carre, P., Pages, X., et al. (2014). Evaluation of alternative solvents for improvement of oil extraction from rapeseeds. Comptes Rendus Chimie, 17, 242-251.

Lis-Balchin, M., Deans, S. G., \& Eaglesham, E. (1998). Relationship between bioactivity and chemical composition of commercial essential oils. Flavour and Fragrance Journal, 13, 98-104.

Loo, A., \& Richard, H. (1992). Origine et propriétés des épices et des aromates bruts In Épices et Aromates (pp. 18-22). France: TEC and DOC-Lavoisier.

Marinova, E. M., \& Yanishlieva, N. V. (1997). Antioxidative activity of extracts from selected species of the family Lamiaceae in sunflower oil. Food Chemistry, 58 245-248.

Moldão-Martins, M., Beirão-da-Costa, S., Neves, C., Cavaleiro, C., Salgueiro, L., \& Beirão-da-Costa, M. L. (2007). Olive oil flavoured by the essential oils of Mentha $\times$ piperita and Thymus mastichina L. Food Quality and Preference, 15, 447-452.

Moldão-Martins, M., Palavra, A., Beirão-da-Costa, M. L., \& Bernardo-Gil, M. G. (2000). Supercritical $\mathrm{CO}_{2}$ extraction of Thymus zygis L. subsp. sylvestris aroma. The Journal of Supercritical Fluids, 18, 35-47.

Orhan, I., Ozçelik, B., \& Sener, B. (2011). Evaluation of antibacterial, antifungal, antiviral, and antioxidant potentials of some edible oils and their fatty acid profiles. Turkish Journal of Biology, 35, 251-258.

Pingret, D., Durand, G., Fabiano-Tixier, A. S., Rockenbauer, A., Ginies, C. \& Chemat, F. (2012). Degradation of edible oil during food processing by ultrasound: electron paramagnetic resonance, physiochemical, and sensory appreciation. Journal of Agricultural and Food Chemistry, 60, 7761-7768.

Prakash, V. (1990). Leafy spices. USA: CRC Press.

Rossignol-Castera, A. (2010). Methods for extracting non-volatile compounds. International patent WO 2010112760 A1.

Sun, M., \& Temelli, F. (2006). Supercritical carbon dioxide extraction of carotenoids from carrots using canola oil as continuous co-solvent. The Journal of Supercritical Fluids, 37, 397-408.

Tomaino, A., Cimino, F. Zimbalatti, V., Venuti, V., Sulfaro, V., De Pasquale, A., et al. (2005). Influence of heating on antioxidant activity and the chemical composition of some spice essential oils. Food Chemistry, 89, 549-554.

Van Boom, S. S., Van der Brugghen, R., \& Maitland, R. (2002). Method for flavoring an olive oil. U.S. patent $0164413 \mathrm{~A} 1$.

Veillet, S., Tomao, V., \& Chemat, F. (2010). Ultrasound assisted maceration: an original procedure for direct aromatization of olive oil with basil. Food Chemistry, 123, 905-911.

Veronezi, C. M., Costa, T., \& Jorge, N. (2012). Basil (Ocimum basilicum L.) as a natural antioxidant. Journal of Food Processing and Preservation. http://dx.doi.org/ 10.1111/j.1745-4549.2012.00771.x. 